\title{
Well-being, Perceived Stress and Their Relations with Health-Relevant Behaviours Among Italian Medical Students: a Cross-Sectional Study at Sapienza University of Rome
}

\author{
Matteo Carpi ${ }^{1}$ - Alberto Milanese ${ }^{2} \cdot$ Maria Sofia Cattaruzza $^{2} \cdot$ Carla Ferrara $^{3}$. \\ Michaela Liuccio ${ }^{2} \cdot$ Annarita Vestri $^{2}$
}

Accepted: 14 October 2021 / Published online: 2 November 2021

(c) Associação Brasileira de Psicologia 2021

\begin{abstract}
Medical education is widely known to be demanding and stressful, with elevated levels of anxiety and depression among medical students. This study aims at examining well-being, perceived stress and quality of life in a sample of Italian first-year medical students in order to investigate the relations between these variables and individual characteristics and behaviours. An anonymous cross-sectional questionnaire was administered to a sample of 407 Italian first-year medical students. Psychological well-being, perceived stress and quality of life were assessed using standardised questionnaires PGWBI, PSS, SF-12. Data were analysed with multivariate statistical methods. Significant differences in PGWBI, PSS and SF-12 scores were found between males and females (with poorer scores for females), between smokers and non-smokers (with poorer scores for smokers) and between students who reported cannabis use in their lifetime and students who did not (with poorer scores for those who smoked cannabis). Logistic regression showed that gender (OR 0.38, 95\% CI 0.24-0.61), reported cannabis use (OR 1.82, 95\% CI 1.07-3.09) and regular physical exercise (OR $0.54,95 \%$ CI $0.34-0.86$ ) were significant predictors of distress. In summary, this study shows that female medical students and students who reported negative health behaviours and sporadic drug use reported lower psychological well-being and quality of life and higher stress, while positive health behaviours might prevent distress.
\end{abstract}

Keywords Medical students mental health · Psychological well-being · Perceived stress - Quality of life · Health behaviours · Gender differences

Matteo Carpi

matteo.carpi@uniroma1.it

Extended author information available on the last page of the article 


\section{Introduction}

Youth mental health is a critical public health issue and it has been estimated that mental illness is the main cause of disability for young people between 10 and 24 years of age (Gore et al., 2011). Up to 10-20\% of children and adolescents are affected by mental health problems (Kieling et al., 2011) and this precocious emergence often leads to long-term impairments (Schleider et al., 2020). Indeed, most mental health problems occur during adolescence and early adulthood (Mughal \& England, 2016), and the period of university studies is particularly critical (Said et al., 2013; Storrie et al., 2010). In the landscape of studies that have dealt with the mental health of university students, a lot of research has focused on medical students, who represent a population particularly at risk and for whom high levels of stress and rates of psychopathology have been documented (Bore et al., 2016; Dyrbye et al., 2006; Zvauya et al., 2017). Medical courses are emotionally demanding and expose students to numerous sources of worry and stress that can produce negative effects in the long run, both on their psychological health and academic performance (Jafari et al., 2012; Radcliffe \& Lester, 2003; Slavin et al., 2014).

Distress and mental health problems reported for medical students appear to remain stable throughout the years of study and training (Guthrie et al., 1998; Rosal et al., 1997; Willcock et al., 2004) and even after employment. Physicians frequently experience distress, burnout and depression, show a higher suicide rate than the general population (Center et al., 2003; Gold et al., 2013; Moutier, 2018) and are unwilling to seek help, often for reasons linked to the fear of being stigmatised due to their professional role (Chew-Graham et al., 2003; Dunn et al., 2009). The issue of gender differences is also part of the picture, especially considering the clear feminization trend of the medical profession observed in recent decades (Arrizabalaga et al., 2015; Fond et al., 2018). Consistently with extensive evidence pointing to a higher risk of anxiety and depressive disorders and higher levels of chronic stress for the female population (Leach et al., 2008; Matud, 2004; Seedat et al., 2009), among medical students, women report lower levels of quality of life (Serinolli \& Novaretti, 2017), greater symptoms of depression and higher risks of burnout (Burger \& Scholz, 2018), whereas males show a greater propensity for using psychotropic drugs and seeking professional help for mental health issues (Fond et al., 2018). This last finding is noteworthy since the larger reported difficulties are usually paired with a more positive attitude towards help seeking among female university students (Nam et al., 2010), and the contradictory trend reported for female medical students might highlight a particularly critical condition characterised by high distress and low intention to seek help.

In a broader context, a systematic review of 40 studies conducted on a sample of Canadian and US medical students (Dyrbye et al., 2006) found a significant prevalence of clinical manifestations of anxiety and depression together with high levels of psychological distress among aspiring doctors. Specifically, in the studies examined in this review, the percentage of medical students reporting symptoms of depression ranged between 13 and $24 \%$ and the overall condition of medical students appeared worse than that of the general population. However, no studies found 
significant differences in distress between medical students and students attending other courses. Results converging with these findings with respect to medical students' mental health were also observed on English (Farrell et al., 2019), Australian (Leahy et al., 2010), Swedish (Dahlin \& Runeson, 2007), Norwegian (Midtgaard et al., 2008), Spanish (Sender et al., 2004) and Brazilian (Pacheco et al., 2017) medical students and a meta-analysis (Mata et al., 2015) including studies conducted in North America, Europe, Asia, South America and Africa provided an updated estimate of $28 \%$ for the prevalence of depression among aspiring doctors.

With reference to the Italian context, in a recent study conducted by Volpe and colleagues (2019) on 360 medical students, $8.6 \%$ of the sample reported at least one mental health problem attributable to a clinically relevant disorder, $8.9 \%$ reported problems related to the use of alcoholic beverages and $22.8 \%$ admitted to having used illicit substances.

These data underline the need for a careful assessment of the psychological wellbeing and stress load of medical students. This process should consider those variables that may play a role in promoting the well-being of future doctors (Dunn et al., 2008; Slavin et al., 2014) with a particular emphasis on individual factors such as health relevant habits and behaviours, whose relationships with mental health have been consistently showed (Bore et al., 2016; Brehm et al., 2016; Terebessy et al., 2016). Identifying specific variables associated with students' distress is indeed the first step in planning preventive interventions as part of the educational curricula.

This study aims to investigate the levels of psychological well-being, stress and quality of life in a sample of students enrolled in the first year of a medical course at Sapienza University of Rome, one of the most important public universities in Italy, with the following objectives:

1. monitoring the entry condition of a convenience sample of medical students with regard to the main dimensions of psychological well-being, perceived stress and quality of life, with particular attention to gender differences;

2. investigating the relationships between psychological well-being, perceived stress and quality of life;

3. assessing habits, characteristics and behaviours relevant to health (physical exercise, alcohol consumption, cigarette smoking, body weight, use of illicit substances, etc.) and their association with levels of psychological well-being and perceived stress.

\section{Methods}

\section{Participants}

A total of 407 students enrolled in the first year of the degree course in Medicine and Surgery at Sapienza University of Rome were involved in the study. Questionnaires were administered in paper format during lesson time in the first semester of the academic year, from October 2016 to January 2017. The survey objectives and 
characteristics were illustrated to the classroom by a researcher and the students participated on a voluntary basis; anonymity and confidentiality were guaranteed. The project was approved by the competent Ethics Committee at Sapienza University of Rome. All participants provided informed consent.

\section{Instruments}

The questionnaire used consisted of three standardised instruments which will be described below, preceded by an ad hoc socio-demographic section designed to collect information on demographics characteristics (age, gender, nationality), body weight and height, drugs medical prescriptions in the last year, and behavioural habits relevant to health (physical exercise or sport sessions per week, frequency of cigarette smoking and alcohol consumption, having tried cannabis).

In order to investigate the domains of physical and psychological well-being and perceived stress, the Short Form 12 self-report questionnaire was administered (SF12; Ware et al., 1996; Italian adaptation by Apolone et al., 2005), along with the Psychological General Well-Being Index (PGWBI; Dupuy, 1990; Italian adaptation by Grossi et al., 2002) and the Perceived Stress Scale (PSS; Cohen et al., 1983).

Short Form 12 It is a shortened version of the SF-36 tool, consisting of 12 items that ask respondents to consider their health status over the last 4 weeks and measure eight domains: physical activity (PF), role and physical health (PR), role and emotional state (RE), mental health $(\mathrm{MH})$, physical pain $(\mathrm{BP})$, general health $(\mathrm{GH})$, vitality (VT) and social activities (SF) (Ware et al., 1996). The domains can be aggregated into two synthetic indexes, the Physical Component Summary (PCS) and the Mental Component Summary (MCS), which report the level of general physical health and general mental health, respectively, for which standardised scores can be obtained with a mean of 50 and a standard deviation of 10, where higher scores correspond to better well-being. The Italian version translated and adapted by Apolone and collaborators (2005), which showed good psychometric properties in the context of population surveys, was used for this study.

Psychological General Well-Being Index This questionnaire measures subjective well-being and psychological distress. It consists of 22 items referring to the last four weeks whose scores can be added to obtain an overall score of psychological well-being. Six specific scores for the dimensions of general health, positive wellbeing, vitality, depression, anxiety and self-control can be obtained (Dupuy, 1990). A higher score-both for the total index and the subscales-corresponds to a higher level of well-being. This is a widely used tool, whose validity has been confirmed in recent studies (Lundgren-Nilsson et al., 2013). For this study, the Italian version adapted by Grossi and collaborators (2002) was administered.

Perceived Stress Scale This is a 10-item questionnaire that measures the degree of perceived stress over the last month. Since its first publication (Cohen et al., 1983), it has been widely used in the literature on heterogeneous populations. Recent studies 
have confirmed its validity also on samples of Italian subjects (Mondo et al., 2019; Nielsen et al., 2016). Higher scores correspond to higher stress levels.

\section{Statistical analyses}

Descriptive statistics were used to summarise the data: numerical variables were summarised as mean and standard deviation or median and interquartile range, respectively, according to the distribution of the data; categorical variables were represented as frequencies and proportions. Student's $t$-test or Wilcoxon test were applied to compare continuous variables, while Fisher's exact test or Chi-Squared test were used to examine the association between categorical variables. Cronbach's alpha coefficient was used to examine the reliability of the SF-12, the PGWBI and the PSS. The correlation between the questionnaire scores was evaluated using Pearson's correlation coefficients. To identify the predictive value of the variables examined with respect to psychological distress outcomes, a logistic regression analysis was performed, considering as the dependent variable an estimate of psychological distress obtained from the PSS score. The results with $p$-value $<0.05$ were considered significant. All analysis was performed with SPSS software (version 25.0, SPSS, Chicago, IL, USA).

\section{Results}

\section{Demographic characteristics}

Out of the 407 students involved, 369 (137 males, 225 females, 7 cases of undeclared sex) answered the questionnaires validly (with a $90.6 \%$ response rate); their average age was 19.72 years (2.15 SD). A total of 343 students reported being Italian nationals, 26 foreign.

\section{Psychometric properties of the PSS, PGWBI and SF-12 questionnaires and relationships between the scales}

The reliability analysis based on Cronbach's alpha coefficient confirmed the good psychometric properties of the instruments administered in the sample under examination. According to conventional criteria (Nunnally \& Bernstein, 1994), an excellent reliability was found for the PGWBI, with a 0.92 coefficient, a good reliability for the PSS, with a 0.88 coefficient and a satisfactory reliability for the SF-12, with a 0.79 coefficient.

Regarding the relationships between the different scales, statistically significant and high correlations were found between the MCS index and the total PGWBI $(r=0.803 ; p<0.01)$, between the MCS and the PSS $(r=-0.779$; $p<0.01)$ and between the PGWBI total score and the PSS $(r=-0.850 ; p<0.01)$; the correlation between the two SF-12 PCS and MCS indexes was significant but small $(r=-0.219 ; p<0.01)$. Significant correlations with the MCS and the PSS 
were also found for all the PGBWI subscales $(p<0.01)$; the General Health and Vitality subscales also correlated with the PCS index (respectively, $r=0.343$; $p<0.01$ and $r=0.111 ; p<0.05)$.

As expected, the correlations between the MCS and the PGWBI (total and subscales) were positive; higher MCS scores corresponded to higher PGWBI scores. The correlations between the PCS and the MCS, between the MCS and the PSS and between the PGWBI (total and subscales) and the PSS were instead inverse, which means that as the score of one scale increases, the score of the other decreases. The correlation coefficients are shown in full in Table 1.

\section{Health-relevant characteristics and behaviours}

The students' responses were codified and analysed to identify those who claimed to smoke cigarettes, habitually drink alcoholic beverages, exercise regularly and have at least one experience of cannabis consumption. The body mass index (BMI) was computed from the weight and height data provided as the ratio between body mass and squared body height in $\mathrm{kg} / \mathrm{m}^{2}$. The data relating to behaviours relevant to health with the relative gender differences by percentage frequency are shown in Table 2. Two statistically significant results emerged: a greater proportion of males over females habitually used alcohol $\left(\chi^{2}=11.16 ; p<0.01\right)$; a greater proportion of male subjects reported a higher than 25 body mass index $\left(\chi^{2}=13.95 ; p<0.01\right)$. As for the use of drugs, 288 students reported having received at least one medical prescription in the past year and-regarding mental health issues in particular-55 students reported being prescribed analgesic drugs and 11 students antidepressant drugs.

\section{Scores on PSS, PGWBI and SF-12 questionnaires}

Table 3 shows the mean scores obtained on the questionnaires for the total sample and grouped by gender for the total scales (PSS, PGWBI, PCS and MCS) as well as the six PGWBI subscales. There were significant differences between the two genders in the PSS $(t=-4.77 ; p<0.01)$, where females scored higher, in the MCS index $(t=3.99 ; p<0.01)$, in the PGWBI total score $(t=3.61, p<0.01)$ and in the subscales anxiety $(t=3.6, p<0.01)$, depression $(t=2.43, p<0.05)$, positive wellness $(t=3.35, p<0.01)$, self-control $(t=3.41, p<0.01)$ and vitality $(t=2.15, p<0.05)$, where males showed higher means. Overall, male students showed lower perceived stress and higher psychological well-being and general mental health scores than female students.

Next, Table 4 shows the mean scores for the total scales of the subjects grouped with respect to behaviours relevant to health and BMI. Among students who declared to be smokers, there was a significantly higher mean score for the PSS $(p<0.05)$; moreover, among those who reported to have tried out smoking cannabis, there was a higher score for the PSS $(p<0.01)$ and significantly lower mean scores for the PGWBI $(p<0.01)$ and the MCS index $(p<0.05)$. 


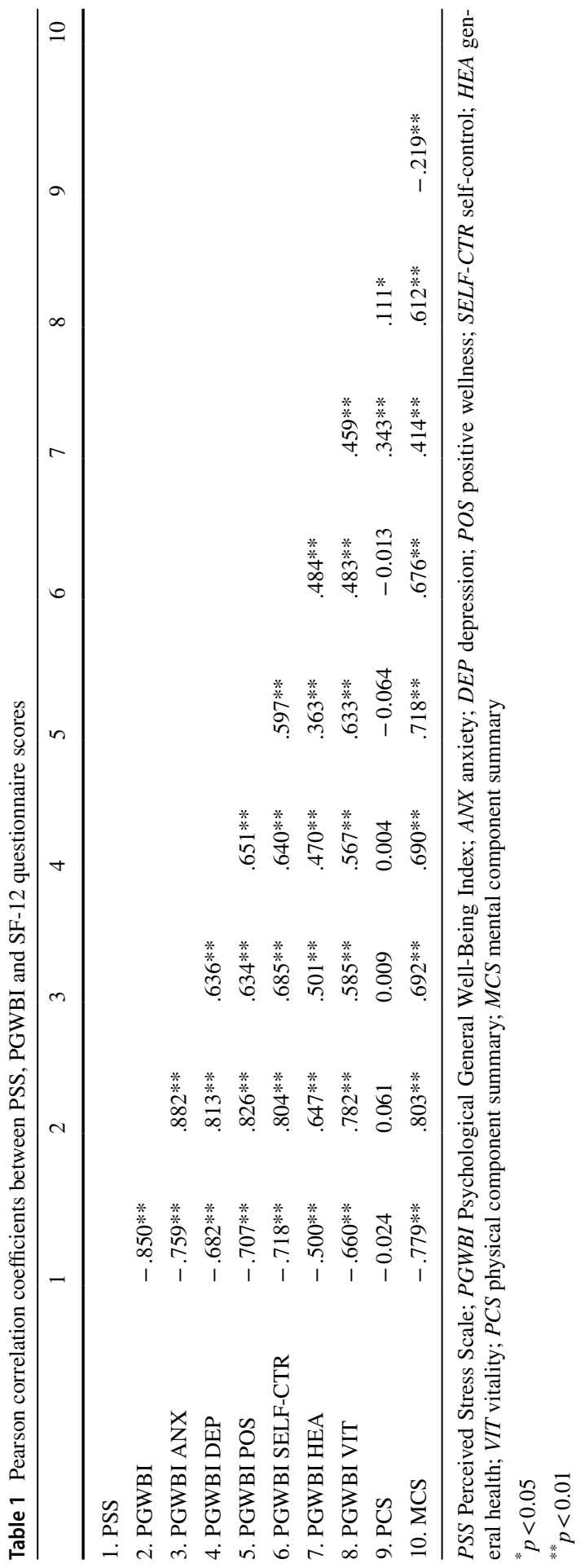


Table 2 Percentage frequencies of health-relevant behaviours and differences between males and females

\begin{tabular}{lllcc}
\hline & $\begin{array}{l}\text { Total }(n=369 \\
(\%))\end{array}$ & $\mathrm{M}(n=137(\%))$ & $\mathrm{F}(n=225(\%))$ & $\chi^{2}$ \\
\hline Cigarette smoking & 22.4 & 19.0 & 24.4 & 1.46 \\
Regular physical activity & 36.2 & 39.4 & 34.2 & 0.99 \\
Habitual use of alcohol & 24.9 & 34.3 & 19.1 & $10.52^{* *}$ \\
Tried cannabis & 38.1 & 36.5 & 39.1 & 0.25 \\
BMI $>25$ & 10.5 & 18.2 & 5.8 & $14.09^{* *}$ \\
\hline
\end{tabular}

$B M I$ body mass index

${ }^{*} p<0.05$

*** $p<0.01$

Table 3 Mean PSS, PGWBI total and subscales and SF-12 scores for male and female students

\begin{tabular}{|c|c|c|c|c|c|c|c|}
\hline & \multicolumn{2}{|l|}{ Total } & \multicolumn{2}{|l|}{ M } & \multicolumn{2}{|l|}{$\mathrm{F}$} & \multirow[b]{2}{*}{$t$} \\
\hline & Mean & SD & Mean & $\mathrm{SD}$ & Mean & SD & \\
\hline PSS & 15.73 & 6.58 & 13.63 & 6.29 & 16.89 & 6.33 & $-4.77 * *$ \\
\hline PGWBI & 74.64 & 14.18 & 78.13 & 14.7 & 72.73 & 13.25 & $3.61 * *$ \\
\hline PGWBI ANX & 15.77 & 4.53 & 16.89 & 4.73 & 15.16 & 4.26 & $3.6 * *$ \\
\hline PGWBI DEP & 12.12 & 2.32 & 12.5 & 2.44 & 11.9 & 2.22 & $2.43 *$ \\
\hline PGWBI POS & 11.63 & 3.26 & 12.39 & 3.4 & 11.24 & 3.01 & $3.35 * *$ \\
\hline PGWBI SELF-CTR & 11.19 & 2.44 & 11.76 & 2.18 & 10.89 & 2.46 & $3.41 * *$ \\
\hline PGWBI HEA & 11.97 & 2.12 & 12.19 & 2.09 & 11.82 & 2.15 & 1.62 \\
\hline PGWBI VIT & 11.96 & 2.91 & 12.4 & 3.1 & 11.73 & 2.71 & $2.15 *$ \\
\hline PCS & 55.21 & 5.62 & 55.29 & 4.95 & 55.06 & 6.03 & 0.39 \\
\hline MCS & 42.43 & 10.79 & 45.39 & 10.76 & 40.87 & 10.28 & $3.99 * *$ \\
\hline
\end{tabular}

PSS Perceived Stress Scale; PGWBI Psychological General Well-Being Index; $A N X$ anxiety; DEP depression; POS positive wellness; SELF-CTR self-control; HEA general health; VIT vitality; PCS physical component summary; $M C S$ mental component summary

${ }^{*} p<0.05$

${ }^{* *} p<0.01$

\section{Relationship between psychological distress and health-relevant behaviours}

In order to explore the relationship between the psychological domains investigated by the questionnaires and the behaviours relevant to health, a binomial logistic regression was conducted considering as the dependent variable the presence of at least moderate distress, estimated from the PSS score considering a score greater than or equal to 14 as indicative of distress consistently with some previous contributions (Kim et al., 2017; Swaminathan et al., 2016). For these analyses, we opted not to consider the scores from the PGWBI and SF-12 questionnaire because of the multidimensional nature of these tools, which makes it difficult to identify reliable and clinically relevant cut-off scores. 
Table 4 Means and standard deviations of PSS, PGWBI, PCS12 and MCS12 scores grouped by healthrelevant behaviours and body mass index

\begin{tabular}{|c|c|c|c|c|}
\hline Answer & PSS & PGWBI & PCS12 & MCS12 \\
\hline \multicolumn{5}{|c|}{ Cigarette smoking } \\
\hline Yes & $17.2 \pm 5.95^{*}$ & $72.28 \pm 13.75$ & $55.6 \pm 4.96$ & $40.41 \pm 10.83$ \\
\hline No & $15.3 \pm 6.7^{*}$ & $75.33 \pm 14.25$ & $55.1 \pm 5.8$ & $43.01 \pm 10.72$ \\
\hline \multicolumn{5}{|c|}{ Regular physical activity } \\
\hline Yes & $15.01 \pm 6.75$ & $76.25 \pm 13.94$ & $55.68 \pm 5.38$ & $42.64 \pm 11.04$ \\
\hline No & $16.14 \pm 6.45$ & $73.71 \pm 14.26$ & $54.94 \pm 5.74$ & $42.30 \pm 10.65$ \\
\hline \multicolumn{5}{|c|}{ Habitual use of alcohol } \\
\hline Yes & $15.70 \pm 5.96$ & $76.37 \pm 14.18$ & $55.05 \pm 4.97$ & $44.18 \pm 10.32$ \\
\hline No & $15.73 \pm 6.78$ & $74.07 \pm 14.16$ & $55.26 \pm 5.82$ & $41.85 \pm 10.89$ \\
\hline \multicolumn{5}{|c|}{ Tried cannabis } \\
\hline Yes & $17.16 \pm 6.38^{* *}$ & $71.45 \pm 14.86^{* *}$ & $55.33 \pm 5.40$ & $40.80 \pm 10.91^{*}$ \\
\hline No & $14.84 \pm 6.55^{* *}$ & $76.61 \pm 13.40^{* *}$ & $55.14 \pm 5.75$ & $43.43 \pm 10.60 *$ \\
\hline \multicolumn{5}{|c|}{$\mathrm{BMI}>25$} \\
\hline Yes & $14.64 \pm 6.62$ & $75.23 \pm 14.37$ & $55.20 \pm 5.34$ & $42.81 \pm 11.87$ \\
\hline No & $15.85 \pm 6.57$ & $74.57 \pm 14.18$ & $55.21 \pm 5.66$ & $42.38 \pm 10.67$ \\
\hline
\end{tabular}

PSS Perceived Stress Scale; PGWBI Psychological General Well-Being Index; PCS physical component summary; $M C S$ mental component summary; $B M I$ body mass index

${ }^{*} p<0.05$

${ }^{* * *} p<0.01$

The logistic regression analysis was conducted on 362 subjects ( 7 subjects who did not declare their gender were excluded) and considered six independent variables (gender, habitual use of alcohol, tried cannabis, cigarette smoking, regular physical activity, BMI > 25) as a single block. Age was not included in the independent variables due to its low variability in the sample under examination. The gender variable was coded with a value of 0 for females and 1 for males, whereas for the other independent variables, the value 1 corresponded to the presence of the related behaviour or characteristic.

The complete model was statistically significant $\left(\chi^{2}=40.01\right.$ with 6 degrees of freedom, $p<0.01)$ and able to discriminate between students with at least moderate levels of distress and students without distress, explaining a variance percentage between 10.5 and $14.3 \%$ of the perceived stress $\left(R^{2}\right.$ of Cox and Snell $=0.15$; $R^{2}$ of Nagelkerke $=0.143$ ) and correctly classifying $67.7 \%$ of the cases. Table 5 shows the regression coefficients and odds ratios (OR) for the predictors considered in the model. For the three independent variables, gender $(p<0.01)$, tried cannabis $(p<0.05)$ and regular physical activity $(p<0.05)$, a statistically significant contribution was found. As far as gender, males showed to be significantly less at risk of distress than females $(\mathrm{OR}=0.38)$; female students are being more than twice as likely to show at least moderate levels of psychological distress. As to the other factors, those who tried cannabis were twice as likely to obtain a PSS 
Table 5 Logistic regression model with psychological distress as a dependent variable (PSS score $\geq 14$ )

\begin{tabular}{lllll}
\hline & B & Wald test & OR & $95 \%$ CI \\
\hline Gender & -0.97 & $16.22 * *$ & 0.38 & $0.24-0.61$ \\
Habitual use of alcohol & -0.29 & 0.96 & 0.74 & $0.41-1.34$ \\
Tried cannabis & 0.6 & $4.89 *$ & 1.82 & $1.07-3.09$ \\
Cigarette smoking & 0.43 & 1.64 & 1.54 & $0.80-2.96$ \\
Regular physical activity & -0.62 & $6.59 *$ & 0.54 & $0.34-0.86$ \\
BMI $>25$ & -0.47 & 1.59 & 0.62 & $0.3-1.3$ \\
\hline
\end{tabular}

$O R$ odds ratio; $C I$ confidence interval

${ }^{*} p<0.05$

${ }^{* *} p<0.01$

score indicating distress $(\mathrm{OR}=1.82)$. Conversely, regular physical activity was associated with a lower risk of distress $(\mathrm{OR}=0.54)$.

\section{Discussion}

In the broader context of the literature on the well-being and mental health of medical students, the results of this study contribute to shed light on the Italian medical students' situation, which had not been widely investigated to date. Overall, the findings of this research-which employed measurement instruments widely used in the literature and which were confirmed to be reliable in the sample under examination-showed psychological well-being scores substantially consistent with the average data of the Italian population for the six PGWBI subscales, although the total score mean was lower than that observed for the general population (Grossi et al., 2002) and fell below the lower range limit of normal scores (78-83) originally identified for the instrument (Dupuy, 1990). With respect to the SF-12 questionnaire, the average for the physical health score PCS-12 was-as expected because of the young age of the sample-higher than that of the general population used for the Italian validation of the tool (Apolone et al., 2005) and had a low variability. Conversely, for the mental health index MCS-12, the average student score was lower than the general population mean and fell below the 25 th percentile.

No normative data for the PSS have been published to our knowledge for Italian students and so it is not possible to compare the results obtained with well-established reference scores. However, it is interesting to observe that the scores for our sample are similar to those obtained when using the instrument on samples of medical students in other European countries (Zvauya et al., 2017).

For what concerns behaviours relevant to health, a high percentage of the students surveyed reported experimenting with illicit substances (cannabis; $38.1 \%$ ), habitually consuming alcoholic beverages (24.9\%) and smoking cigarettes (22.4\%). In addition, cigarette smokers in the sample under consideration had significantly higher scores of perceived stress, as did those who tried cannabis, which also showed significantly lower scores in psychological well-being and general mental 
health. These latter results in particular are consistent with previous studies, which have shown an association both between cigarette smoking and psychological problems (Cranford et al., 2009; Patterson et al., 2004) and between cannabis use and psychopathological symptoms in college students populations (Keith et al., 2015).

Overall, these preliminary data are consistent with the results of the international literature previously cited, which suggest that we should pay attention to the issue of psychological distress among medical students and highlight the importance of identifying behaviours at risk (Bore et al., 2016; Dyrbye et al., 2006).

Regarding gender differences, female students were found to have higher levels of perceived stress and lower levels of general mental health and psychological wellbeing (both in relation to the PGWBI total score its subscales anxiety, depression, positive wellness, self-control and vitality). On the other hand, among males, the proportion of students habitually using alcoholic beverages and those with a body mass index greater than 25 were found to be greater. These results are consistent with the other studies mentioned above, which highlight higher levels of psychological distress among female medical students (Burger \& Scholz, 2018; Dahlin et al., 2005; Serinolli \& Novaretti, 2017) compared to a greater propensity for male students to drink alcohol and assume substances (Fond et al., 2018).

The examination of the relationship between the scales used showed significant strong negative correlations between psychological well-being detected with the PGWBI and perceived stress detected with the PSS, and between general mental health (MCS index of the SF-12 questionnaire) and perceived stress. These datapreviously found in a sample of dentistry students (Sugiura et al., 2005)—corroborates the construct validity of the measuring tools used and shows a correspondence between high levels of perceived stress and worse outcomes in terms of general psychological well-being and mental health. In order to further explore these findings, the predictive value of gender and behaviours relevant to health with respect to the experience of psychological distress was investigated by means of a binomial logistic regression model, considering as the dependent variable a dichotomous estimate of distress obtained from the PSS score. Female gender and having tried cannabis were associated with higher levels of distress, whereas regular physical activity was shown to be associated with less distress, consistently with previous studies (McFadden et al., 2020; Sugiura et al., 2005).

This general picture encourages the planning and implementation of interventions aimed at preventing psychological distress in medical students which should be integrated in the study curriculum (Dunn et al., 2008; Slavin et al., 2014). In this context, particular attention should be devoted to stress management and behaviours relevant to health, both by promoting virtuous conducts (e.g., regular physical activity, healthy eating) and preventing behaviours at risk (especially substance use and abuse). Self-care strategies could play a key role for this purpose too, given the growing evidence for their effectiveness and feasibility. Indeed, several studies showed that specific mindfulness meditation protocols might be effective in reducing distress and emotional symptoms and promoting well-being and emotion regulation skills (Galante et al., 2018; Van Gordon et al., 2014) whereas rapidly teachable relaxation techniques could help students to reduce their anxiety levels (Aritzeta et al., 2017; Ozamiz-Etxebarria et al., 2020). 
As a whole, these efforts towards effective solutions take on significant importance considering the current challenges and difficulties caused by the COVID-19 pandemic to the student population and medical students in particular (Chandratre, 2020).

Finally, some limitations of this study should be taken into account when interpreting the results presented in this paper. Although the response rate was remarkable, the sample involved is indeed not representative, as it was composed exclusively of medical students enrolled in the first-year course of a single university. Therefore, our findings pertain to the characteristics of this specific population, and an over-representation of the female gender further limits generalisability. This is particularly relevant due to the substantial impact of gender and cultural factors on the investigated domains (Burger and Scholz, 2018; Fond et al., 2018; Grossi et al., 2012). Furthermore, we adopted a cross-sectional singlegroup research design, which does not allow conclusions with respect to causal links; further longitudinal studies are needed to shed light on the hypotheses of association between variables formulated in this paper. Direct comparisons with homologous groups of students attending other university courses with respect to mental health and well-being outcomes might as well be conducted in order to better address the specificity of the condition of medical students. Lastly, the use of illicit substances-for which a significant association was observed with psychological distress - was investigated by means of a single question about the experience of having tried out cannabis in the past; this type of behaviour should be examined more in depth with specific questions about recent events, in consideration of the role they seem to play in the mental health of the student population (Cranford et al., 2009). Subsequent research will be able to investigate these aspects, also in relation to the impact of COVID-19 pandemic-related restrictions on the psychological well-being and mental health of university students.

\section{Conclusions}

In conclusion, our results are consistent with the previous literature on medical students' mental health. On the whole, our sample of first-year medical students showed moderate level of distress, with worse scores for female students on all the dimensions examined (perceived stress, psychological well-being and SF-12 general mental health) and a higher rate of alcohol consumption among male students. Moreover, female gender and previous substance use (cannabis) resulted to be risk factors for psychological distress; regular physical exercise was instead identified as a protective factor associated with lower psychological distress. Although further research should confirm these results on wider samples and longitudinal studies need to be conducted in order to better explore causal relationships between individual variables and mental health outcomes, taken together, these findings might inform preventive interventions aimed at reducing medical students' distress and promoting well-being among future doctors. 
Availability of data and material The data that support the results of this study are available from the corresponding author upon reasonable request.

\section{Declarations}

Ethics approval This study was approved by Sapienza University of Rome Ethics Committee (protocol number 241/18).

Consent to participate All subjects involved provided informed consent to participate to this study.

Consent for publication All participants expressed their consent to the publication of the collected data and the relative results in an aggregated form.

Conflict of Interest The authors declare no competing interests.

\section{References}

Apolone, G., Mosconi, P., Quattrociocchi, L., Granicolo, E. A. L., Groth, N., \& Ware Jr, J. E. (2005). Questionario sullo stato di health SF-12 Versione Italiana. Istituto di Ricerche Farmacologiche "Mario Negri", Milano.

Aritzeta, A., Soroa, G., Balluerka, N., Muela, A., Gorostiaga, A., \& Aliri, J. (2017). Reducing anxiety and improving academic performance through a biofeedback relaxation training program. Applied Psychophysiology and Biofeedback, 42(3), 193-202. https://doi.org/10.1007/s10484-017-9367-z

Arrizabalaga, P., Abellana, R., Viñas, O., Merino, A., \& Ascaso, C. (2015). Women doctors and their careers in a large university hospital in Spain at the beginning of the 21st century. Human Resources for Health, 13(1), 1-8. https://doi.org/10.1186/s12960-015-0008-4

Bore, M., Kelly, B., \& Nair, B. (2016). Potential predictors of psychological distress and well-being in medical students: A cross-sectional pilot study. Advances in Medical Education and practice, 7 , 125-135. https://doi.org/10.2147/AMEP.S96802

Brehm, B. J., Summer, S. S., Khoury, J. C., Filak, A. T., Lieberman, M. A., \& Heubi, J. E. (2016). Health status and lifestyle habits of US medical students: A longitudinal study. Annals of Medical and Health Sciences Research, 6(6), 341-347. https://doi.org/10.4103/amhsr.amhsr_469_15

Burger, P. H. M., \& Scholz, M. (2018). Gender as an underestimated factor in mental health of medical students. Annals of Anatomy-Anatomischer Anzeiger, 218, 1-6. https://doi.org/10.1016/j.aanat.2018. 02.005

Center, C., Davis, M., Detre, T., Ford, D. E., Hansbrough, W., Hendin, H., Laszlo, J., Litts, D. A., Mann, J., Mansky, P. A., Michels, R., Miles, S. H., Proujansky, R., Reynolds, C. F., 3rd., \& Silverman, M. M. (2003). Confronting depression and suicide in physicians: A consensus statement. JAMA, 289(23), 3161-3166. https://doi.org/10.1001/jama.289.23.3161

Chandratre, S. (2020). Medical students and COVID-19: Challenges and supportive strategies. Journal of Medical Education and Curricular Development, 7, 2382120520935059. https://doi.org/10.1177/ 2382120520935059

Chew-Graham, C. A., Rogers, A., \& Yassin, N. (2003). 'I wouldn't want it on my CV or their records': Medical students' experiences of help-seeking for mental health problems. Medical Education, 37(10), 873-880. https://doi.org/10.1046/j.1365-2923.2003.01627.x

Cohen, S., Kamarck, T., \& Mermelstein, R. (1983). A global measure of perceived stress. Journal of Health and Social Behavior, 385-396. https://psycnet.apa.org/doi/https://doi.org/10.2307/2136404.

Cranford, J. A., Eisenberg, D., \& Serras, A. M. (2009). Substance use behaviors, mental health problems, and use of mental health services in a probability sample of college students. Addictive Behaviors, 34(2), 134-145. https://doi.org/10.1016/j.addbeh.2008.09.004

Dahlin, M., Joneborg, N., \& Runeson, B. (2005). Stress and depression among medical students: A crosssectional study. Medical Education, 39(6), 594-604. https://doi.org/10.1111/j.1365-2929.2005. 02176.x 
Dahlin, M. E., \& Runeson, B. (2007). Burnout and psychiatric morbidity among medical students entering clinical training: A three year prospective questionnaire and interview-based study. BMC Medical Education, 7(1), 6. https://doi.org/10.1186/1472-6920-7-6

Dunn, L. B., Hammond, K. A. G., \& Roberts, L. W. (2009). Delaying care, avoiding stigma: Residents' attitudes toward obtaining personal health care. Academic Medicine, 84(2), 242-250. https://doi.org/ 10.1097/acm.0b013e31819397e2

Dunn, L. B., Iglewicz, A., \& Moutier, C. (2008). A conceptual model of medical student well-being: Promoting resilience and preventing burnout. Academic Psychiatry, 32(1), 44-53. https://doi.org/10. 1176/appi.ap.32.1.44

Dupuy, H. J. (1990). The psychological general well-being (PGWB) index. In N. K. Wenger, M. E. Mattson, C. D. Furburg, \& J. Elinson (Eds.), Assessment of quality of life in clinical trials of cardiovascular therapies (pp. 170-183). Le Jacq Publishing.

Dyrbye, L. N., Thomas, M. R., \& Shanafelt, T. D. (2006). Systematic review of depression, anxiety, and other indicators of psychological distress among US and Canadian medical students. Academic Medicine, 81(4), 354-373. https://doi.org/10.1097/00001888-200604000-00009

Farrell, S. M., Kadhum, M., Lewis, T., Singh, G., Penzenstadler, L., \& Molodynski, A. (2019). Wellbeing and burnout amongst medical students in England. International Review of Psychiatry, 31(7-8), 579-583. https://doi.org/10.1080/09540261.2019.1675960

Fond, G., Bourbon, A., Auquier, P., Micoulaud-Franchi, J. A., Lançon, C., \& Boyer, L. (2018). Venus and Mars on the benches of the faculty: Influence of gender on mental health and behavior of medical students. Results from the BOURBON national study. Journal of Affective Disorders, 239, 146-151. https://doi.org/10.1016/j.jad.2018.07.011

Gold, K. J., Sen, A., \& Schwenk, T. L. (2013). Details on suicide among US physicians: Data from the National Violent Death Reporting System. General Hospital Psychiatry, 35(1), 45-49. https://doi. org/10.1016/j.genhosppsych.2012.08.005

Galante, J., Dufour, G., Vainre, M., Wagner, A. P., Stochl, J., Benton, A., Lathia, N., Howarth, E., \& Jones, P. B. (2018). A mindfulness-based intervention to increase resilience to stress in university students (the Mindful Student Study): A pragmatic randomised controlled trial. The Lancet Public Health, 3(2), e72-e81. https://doi.org/10.1016/S2468-2667(17)30231-1

Gore, F. M., Bloem, P. J., Patton, G. C., Ferguson, J., Joseph, V., Coffey, C., Sawyer, S. M., \& Mathers, C. D. (2011). Global burden of disease in young people aged 10-24 years: A systematic analysis. The Lancet, 377(9783), 2093-2102. https://doi.org/10.1016/S0140-6736(11)60512-6

Grossi, E., Blessi, G. T., Sacco, P. L., \& Buscema, M. (2012). The interaction between culture, health and psychological well-being: Data mining from the Italian culture and well-being project. Journal of Happiness Studies, 13(1), 129-148. https://doi.org/10.1007/s10902-011-9254-X

Grossi, E., Mosconi, P., Groth, N., Niero, M., \& Apolone, G. (2002). Il Questionario Psychological General Well-Being. Questionario per la valutazione dello stato generale di benessere psicologico. Versione Italiana. Istituto di Ricerche Farmacologiche "Mario Negri", Milano.

Guthrie, E., Black, D., Bagalkote, H., Shaw, C., Campbell, M., \& Creed, F. (1998). Psychological stress and burnout in medical students: A five-year prospective longitudinal study. Journal of the Royal Society of Medicine, 91(5), 237-243. https://doi.org/10.1177/014107689809100502

Jafari, N., Loghmani, A., \& Montazeri, A. (2012). Mental health of medical students in different levels of training. International Journal of Preventive Medicine, 3(Suppl1), S107-S112.

Keith, D. R., Hart, C. L., McNeil, M. P., Silver, R., \& Goodwin, R. D. (2015). Frequent cannabis use, binge drinking and mental health problems among undergraduates. The American Journal on Addictions, 24(6), 499-506. https://doi.org/10.1111/ajad.12201

Kieling, C., Baker-Henningham, H., Belfer, M., Conti, G., Ertem, I., Omigbodun, O., Rohde, L. A., Srinath, S., Ulkuer, N., \& Rahman, A. (2011). Child and adolescent mental health worldwide: Evidence for action. Lancet (london, England), 378(9801), 1515-1525. https://doi.org/10.1016/S01406736(11)60827-1

Kim, D. S., Sung, H. H., Lee, J. W., \& Cho, E. K. (2017). The relationship between perceived stress scale and carotid intima-media thickness using ultrasonography in university students. Korean Journal of Clinical Laboratory Science, 49(3), 308-315. https://doi.org/10.15324/kjcls.2017.49.3.308

Leach, L. S., Christensen, H., Mackinnon, A. J., Windsor, T. D., \& Butterworth, P. (2008). Gender differences in depression and anxiety across the adult lifespan: The role of psychosocial mediators. Social Psychiatry and Psychiatric Epidemiology, 43(12), 983-998. https://doi.org/10.1007/ s00127-008-0388-Z 
Leahy, C. M., Peterson, R. F., Wilson, I. G., Newbury, J. W., Tonkin, A. L., \& Turnbull, D. (2010). Distress levels and self-reported treatment rates for medicine, law, psychology and mechanical engineering tertiary students: Cross-sectional study. Australian \& New Zealand Journal of Psychiatry, 44(7), 608-615. https://doi.org/10.3109/00048671003649052

Lundgren-Nilsson, A., Jonsdottir, I. H., Ahlborg, G., \& Tennant, A. (2013). Construct validity of the psychological general well being index (PGWBI) in a sample of patients undergoing treatment for stress-related exhaustion: A Rasch analysis. Health and Quality of Life Outcomes, 11(1), 2. https:// doi.org/10.1186/1477-7525-11-2

Mata, D. A., Ramos, M. A., Bansal, N., Khan, R., Guille, C., Di Angelantonio, E., \& Sen, S. (2015). Prevalence of depression and depressive symptoms among resident physicians: A systematic review and meta-analysis. JAMA, 314(22), 2373-2383. https://doi.org/10.1001/jama.2015.15845

Matud, M. P. (2004). Gender differences in stress and coping styles. Personality and Individual Differences, 37(7), 1401-1415. https://doi.org/10.1016/j.paid.2004.01.010

McFadden, T., Fortier, M., Sweet, S. N., \& Tomasone, J. R. (2020). Physical activity participation and mental health profiles in Canadian medical students: Latent profile analysis using continuous latent profile indicators. Psychology, Health \& Medicine, 1-13. https://doi.org/10.1080/13548506.2020. 1757131.

Midtgaard, M., Ekeberg, Ø., Vaglum, P., \& Tyssen, R. (2008). Mental health treatment needs for medical students: A national longitudinal study. European Psychiatry, 23(7), 505-511. https://psycnet.apa. org/doi/https://doi.org/10.1016/j.eurpsy.2008.04.006.

Mondo, M., Sechi, C., \& Cabras, C. (2019). Psychometric evaluation of three versions of the Italian perceived stress scale. Current Psychology, 1-9. https://link.springer.com/article/https://doi.org/10. 1007/s12144-019-0132-8.

Moutier, C. (2018). Physician mental health: an evidence-based approach to change. Journal of Medical Regulation, 104(2), 7-13. https://doi.org/10.30770/2572-1852-104.2.7

Mughal, F., \& England, E. (2016). The mental health of young people: The view from primary care. British Journal of General Practice, 66(651), 502-503. https://doi.org/10.3399/bjgp16X687133

Nam, S. K., Chu, H. J., Lee, M. K., Lee, J. H., Kim, N., \& Lee, S. M. (2010). A meta-analysis of gender differences in attitudes toward seeking professional psychological help. Journal of American College Health, 59(2), 110-116. https://doi.org/10.1080/07448481.2010.483714

Nielsen, M. G., Ørnbøl, E., Vestergaard, M., Bech, P., Larsen, F. B., Lasgaard, M., \& Christensen, K. S. (2016). The construct validity of the Perceived Stress Scale. Journal of Psychosomatic Research, 84, 22-30. https://doi.org/10.1016/j.jpsychores.2016.03.009

Nunnally, J. C., \& Bernstein, I. H. (1994). Psychometric theory (3rd ed.). McGraw-Hill.

Ozamiz-Etxebarria, N., Santa María, M. D., Munitis, A. E., \& Gorrotxategi, M. P. (2020). Reduction of COVID-19 anxiety levels through relaxation techniques: A study carried out in Northern Spain on a sample of young university students. Frontiers in Psychology, 11, 2038. https://doi.org/10.3389/ fpsyg.2020.02038

Pacheco, J. P., Giacomin, H. T., Tam, W. W., Ribeiro, T. B., Arab, C., Bezerra, I. M., \& Pinasco, G. C. (2017). Mental health problems among medical students in Brazil: A systematic review and meta-analysis. Brazilian Journal of Psychiatry, 39(4), 369-378. https://doi.org/10.1590/ 1516-4446-2017-2223

Patterson, F., Lerman, C., Kaufmann, V. G., Neuner, G. A., \& Audrain-McGovern, J. (2004). Cigarette smoking practices among American college students: Review and future directions. Journal of American College Health, 52(5), 203-212. https://doi.org/10.3200/jach.52.5.203-212

Radcliffe, C., \& Lester, H. (2003). Perceived stress during undergraduate medical training: A qualitative study. Medical Education, 37(1), 32-38. https://doi.org/10.1046/j.1365-2923.2003.01405.x

Rosal, M. C., Ockene, I. S., Ockene, J. K., Barrett, S. V., Ma, Y., \& Hebert, J. R. (1997). A longitudinal study of students' depression at one medical school. Academic Medicine, 72(6), 542-546. https:// doi.org/10.1097/00001888-199706000-00022

Said, D., Kypri, K., \& Bowman, J. (2013). Risk factors for mental disorder among university students in Australia: Findings from a web-based cross-sectional survey. Social Psychiatry and Psychiatric Epidemiology, 48(6), 935-944. https://doi.org/10.1007/s00127-012-0574-x

Schleider, J. L., Dobias, M. L., Sung, J. Y., \& Mullarkey, M. C. (2020). Future directions in single-session youth mental health interventions. Journal of Clinical Child \& Adolescent Psychology, 49(2), 264278. https://doi.org/10.1080/15374416.2019.1683852

Seedat, S., Scott, K. M., Angermeyer, M. C., Berglund, P., Bromet, E. J., Brugha, T. S., Demyttenaere, K., de Girolamo, G., Haro, J. M., Jin, R., Karam, E. G., Kovess-Masfety, V., Levinson, D., Medina 
Mora, M. E., Ono, Y., Ormel, J., Pennell, B. E., Posada-Villa, J., Sampson, N. A., ... Kessler, R. C. (2009). Cross-national associations between gender and mental disorders in the World Health Organization World Mental Health Surveys. Archives of General Psychiatry, 66(7), 785-795. https://doi.org/10.1001/archgenpsychiatry.2009.36

Sender, R., Salamero, M., Vallés, A., \& Valdés, M. (2004). Psychological variables for identifying susceptibility to mental disorders in medical students at the University of Barcelona. Medical Education Online, 9(1), 4350. https://doi.org/10.3402/meo.v9i.4350

Serinolli, M. I., \& Novaretti, M. C. Z. (2017). A cross-sectional study of sociodemographic factors and their influence on quality of life in medical students at Sao Paulo Brazil. Plos One, 12(7), e0180009. https://doi.org/10.1371/journal.pone.0180009

Slavin, S. J., Schindler, D. L., \& Chibnall, J. T. (2014). Medical student mental health 3.0: improving student wellness through curricular changes. Academic Medicine, 89(4), 573-577. https://doi.org/ 10.1097/acm.0000000000000166

Storrie, K., Ahern, K., \& Tuckett, A. (2010). A systematic review: Students with mental health problems-A growing problem. International Journal of Nursing Practice, 16(1), 1-6. https://doi.org/ 10.1111/j.1440-172X.2009.01813.x

Sugiura, G., Shinada, K., \& Kawaguchi, Y. (2005). Psychological well-being and perceptions of stress amongst Japanese dental students. European Journal of Dental Education, 9(1), 17-25. https://doi. org/10.1111/j.1600-0579.2004.00352.x

Swaminathan, A., Viswanathan, S., Gnanadurai, T., Ayyavoo, S., \& Manickam, T. (2016). Perceived stress and sources of stress among first-year medical undergraduate students in a private medical college-Tamil Nadu. National Journal of Physiology, Pharmacy and Pharmacology, 6(1), 9-14. https://doi.org/10.5455/njppp.2015.5.1909201574

Terebessy, A., Czeglédi, E., Balla, B. C., Horváth, F., \& Balázs, P. (2016). Medical students' health behaviour and self-reported mental health status by their country of origin: A cross-sectional study. BMC Psychiatry, 16(1), 171. https://doi.org/10.1186/s12888-016-0884-8

Van Gordon, W., Shonin, E., Sumich, A., Sundin, E. C., \& Griffiths, M. D. (2014). Meditation awareness training (MAT) for psychological well-being in a sub-clinical sample of university students: A controlled pilot study. Mindfulness, 5(4), 381-391. https://doi.org/10.1007/s12671-012-0191-5

Volpe, U., Ventriglio, A., Bellomo, A., Kadhum, M., Lewis, T., Molodynski, A., ... \& Fiorillo, A. (2019). Mental health and wellbeing among Italian medical students: A descriptive study. International Review of Psychiatry, 31(7-8), 569-573. https://doi.org/10.1080/09540261.2019.1654718.

Ware Jr, J. E., Kosinski, M., \& Keller, S. D. (1996). A 12-Item Short-Form Health Survey: construction of scales and preliminary tests of reliability and validity. Medical Care, 220-233. https://doi.org/10. 1097/00005650-199603000-00003.

Willcock, S. M., Daly, M. G., Tennant, C. C., \& Allard, B. J. (2004). Burnout and psychiatric morbidity in new medical graduates. Medical Journal of Australia, 181(7), 357-360. https://doi.org/10.5694/j. 1326-5377.2004.tb06325.x

Zvauya, R., Oyebode, F., Day, E. J., Thomas, C. P., \& Jones, L. A. (2017). A comparison of stress levels, coping styles and psychological morbidity between graduate-entry and traditional undergraduate medical students during the first 2 years at a UK medical school. BMC Research Notes, 10(1), 93. https://doi.org/10.1186/s13104-017-2395-1

\title{
Authors and Affiliations
}

\section{Matteo Carpi ${ }^{1}$ - Alberto Milanese ${ }^{2} \cdot$ Maria Sofia Cattaruzza $^{2} \cdot$ Carla Ferrara $^{3}$. Michaela Liuccio ${ }^{2} \cdot$ Annarita Vestri $^{2}$}

\author{
Alberto Milanese \\ alberto.milanese@uniroma1.it \\ Maria Sofia Cattaruzza \\ mariasofia.cattaruzza@uniroma1.it \\ Carla Ferrara \\ carla.ferrara@uniroma1.it
}


Michaela Liuccio

michaela.liuccio@uniroma1.it

Annarita Vestri

annarita.vestri@uniroma1.it

1 Department of Psychology, Sapienza University of Rome, Via dei Marsi, 78, Piazzale Aldo Moro, 5, 00185 Rome, Italy

2 Department of Public Health and Infectious Diseases, Sapienza University of Rome, Piazzale Aldo Moro, 5, 00185 Rome, Italy

3 Italian National Institute of Health, Viale Regina Elena, 299, 00161 Rome, Italy 